\title{
La naturaleza del rapto según la gnoseología de Tomás de Aquino
}

The Nature of Rapture according to the Gnoseology of St. Thomas Aquinas

Ezequiel Tellez Maqueo

Universidad Panamericana (México)

Recibido: 2015-10-02

Enviado a pares: 2015-10-12

Aprobado por pares: 2015-11-28

Aprobado: 2015-12-03

Pensamiento y Cultura | ISSN: 0123-0999 | elSSN: 2027-5331

pensam.cult | Vol. 18-2 | Diciembre de 2015 | pp. 29-48

DOI: 10.5294/pecu.2015.18.2.2

Para citar este artículo/To reference this article

Tellez Maqueo, Ezequiel. 2015. "La naturaleza del rapto según la

gnoseología de Tomás de Aquino", Pensamiento y Cultura 18 (2): 29-48. DOI: 10.5294/ pecu.2015.18.2.2 


\section{La naturaleza del rapto según la gnoseología de Tomás de Aquino}

Resumen: en este artículo me propongo tratar de responder a las siguientes preguntas: (1) ¿cómo debemos entender el que sea posible tener una visión de Dios en un plano superior, si naturalmente el intelecto sólo puede tener conocimiento de aquello de lo cual se tienen fantasmas e imágenes sensibles? (2) ¿Podría decirse que dicho proceso es algo violento o antinatural, es decir, contrario a la naturaleza del intelecto?

Palabras clave: rapto; gnoseología; filosofía medieval.

\section{The Nature of Rapture according to the Gnoseology of St. Thomas}

\section{Aquinas}

Abstract: In this article, I aim to answer the following questions: (1) How can
we understand the fact that it is possible to have a vision of God on a higher
plane if, naturally, the intellect can only have knowledge of that regarding
which we have phantoms and sensitive images? (2) Can it be said that such
process is something violent or anti-natural, i.e. against the nature of intellect?

Keywords: Rapture; gnoseology; medieval philosophy. 


\section{Planteamiento del problema}

La idea de abandono o de alejamiento de las realidades mundanas, de exceder los propios límites del cuerpo, o de sustraerse definitivamente de la vida corporal y vegetativa, es de lo que Tomás de Aquino se ocupa al tratar el tema del rapto. En general, ser raptado (del lat. rapere, robar) quiere decir ser sustraído de un sitio o lugar. En sentido gnoseológico, en cambio, el rapto es "una cierta elevación del alma desde las cosas sensibles exteriores, por la que el hombre tiende naturalmente, hacia aquellas realidades que están por encima de él".

Llama la atención que en esta descripción del rapto, santo Tomás lo describa como una elevación natural hacia algo superior. Teniendo en cuenta que dicha elevación se produce en virtud de una naturaleza superior -como es la naturaleza divina-, es lógico suponer que santo Tomás estaba implicando con ello que Dios podría actuar contra la propia naturaleza cognoscitiva del hombre, quebrantando el orden natural establecido por Él mismo, y así actuar contra la manera natural de conocer del hombre (a saber, por medio de los sentidos y la inteligencia).

Sin embargo, ello no resultaba aceptable para quienes consideraban que Dios sería incapaz de hacer algo contra-naturaleza. Ellos pensaban que era inadmisible que Dios actuara injustamente, ya que "la justicia divina consiste en dar a cada cosa según la medida y dignidad que les corresponde", 2 y Dios no podía hacer nada contra su justicia. Y así, era justo que el hombre recibiera una determinada naturaleza, y era necesario que nada hiciera Dios contra la misma.

Por esta razón para los maestros agustinianos de París debía ser natural que la inteligencia humana accediese a la visión de la esencia divina, porque, como dice san Agustín, "la inteligencia del hombre

1 De veritate, q. XIII, a. 2, ad 8m. Para la traducción española de las obras aquí citadas de santo Tomás nos hemos servido de la edición de la colección Cuadernos de Anuario, así como de la edición de Eunsa, ambas publicadas por la Universidad de Navarra, según aparece en la lista bibliográfica al final del presente artículo. En casos en los que no se cuente con una versión castellana de la obra citada de Tomás de Aquino, la traducción ha corrido a cargo de nosotros.

2 Pseudo-Dionisio, De divinis nominibus, citado por Tomás de Aquino, De veritate, q. XIII, a. 1 , arg. 4 . 
conoce naturalmente a Dios". ${ }^{3} \mathrm{Y}$ aun si las impresiones provenientes de los cuerpos superiores se producían naturalmente en los cuerpos inferiores - como gustaba de decir Averroes ${ }^{4}$ - ¿por qué no iba a ser natural la elevación de un espíritu inferior como el intelecto humano, producida por un espíritu superior como Dios?

Existía, ciertamente, la creencia filosófica en el siglo XIII que cualquier operación natural era llevada a cabo bajo disposición divina. Es decir, toda operación que forma parte de la naturaleza de algún ente (llevada a cabo por él para alcanzar su fin) no solo tiende a su fin sino que opera porque Dios así lo dispone; razón por la cual dice Tomás de Aquino que «las obras de la naturaleza son obras de una inteligencia». ${ }^{5}$

Pero para tales críticos agustinianos de Alberto y Tomás, esto significaba otra cosa sino que Dios funge como causa final de las operaciones presentes en las criaturas, mas no que necesariamente fuese la causa eficiente y directa de tales operaciones, lo cual correspondía en cambio a las propias potencias operativas de los individuos. Y así, si Dios ha prescrito que las demás operaciones de la naturaleza alcancen el fin que les es propio naturalmente, es decir, por un movimiento que procede de ellas mismas y no por fuerza de una naturaleza superior (piénsese por ejemplo en los árboles, que crecen naturalmente, o los pájaros que se nutren espontáneamente), también tratándose de la mente humana debía ser completamente natural a ella conocer a Dios en el rapto.

Con ocasión de esta temática, Tomás de Aquino tuvo seguramente que encarar las insuficiencias que el sistema filosófico de Aristóteles presentaba frente un fenómeno cognoscitivo, el cual solamente estaba destinado a ser dilucidado bajo las coordenadas del pensamiento cristiano. El naturalismo aristotélico se caracterizaba por afirmar que la

3 Más bien un Pseudo-Agustín, De spiritu et anima, cap. 11 (PL 40, 787). En De veritate, q. VIII, a. 3, arg. 13, Tomás cita la opinión de autores para quienes las potencias inferiores así como los sentidos y la imaginación conocen naturalmente sus objetos. De ahí que entonces siendo Dios el objeto de la inteligencia humana, también será conocido naturalmente.

4 In III De coelo et mundo, comm. 20 (V, 187 F).

5 De veritate, q. III, a. 1, c. En realidad, la idea tomista de que toda obra de la naturaleza se dice que es obra de una inteligencia, ya aparece esbozada en Alberto Magno, De animalibus, I, tr. 2, c. 12, n. 274; y II, tr. 1, c. 1, n. 11 (St. I, 97 y 227). 
naturaleza era el principio de todas las cosas, y se entendía por naturaleza la forma (propiedad que le era inherente al sujeto). Este naturalismo debió ser sometido a un revisionismo tal que dejó de ser posible hablar de operaciones exclusivamente naturales, y agregar también operaciones que rebasaban dicha naturaleza tales como el rapto.

Al fin llegaría el momento de reconocer la existencia de un tipo de operación de la inteligencia en la que los datos exteriores de los sentidos no jugaban un factor relevante en la producción del conocimiento mismo.

En este artículo me propongo tratar de responder a la siguiente pregunta: ¿cómo debemos entender la posibilidad de tener una visión de Dios en un plano superior, si naturalmente el intelecto solo puede tener conocimiento de aquello de lo cual se tienen fantasmas e imágenes sensibles? ¿Podría decirse que dicho proceso es algo violento o antinatural, es decir, contrario a la naturaleza del intelecto? Este es el problema gnoseológico de la violencia del rapto en Tomás.

\section{El rapto como elevación «praeter naturam»}

Los primeros indicios de respuesta hay que buscarlos comenzando por analizar lo que la misma palabra implica. Rapto, como ya fue explicado, indica que se es raptado por otro. Por alguien ajeno al que lo sufre, pues nadie se rapta a sí mismo o por sí mismo. De este modo, no deberá extrañar el resultado al que Tomás de Aquino llegará: afirmar que ciertamente el rapto no es una elevación del alma dependiente de la voluntad, sino más bien imperada desde afuera por fuerza de una naturaleza superior.

Lo que hace que la fuerza de esa naturaleza superior recaiga sobre ciertos individuos y no sobre otros, es algo que por ahora no hace falta responder (se verá cuando se trate sobre las aptitudes morales del sujeto raptable). Lo importante es lo extraordinario del rapto, lo inopinado del mismo al grado que no son legiones quienes históricamente han sufrido alguno, sino más bien sujetos aislados en una zona de "privilegio» cognoscitivo.

Este carácter extraordinario del rapto condujo a Tomás de Aquino a tener que definir, en primer lugar, si la elevación obrada por Dios sobre 
el alma humana constituye un movimiento violento. Y si san Alberto ha definido el rapto como una elevación praeter naturam, es importante detenerse pensar qué se debe de entender por esto.

Para determinarlo, importa mucho distinguir dos clases o procesos preternaturales. Todo aquello que no es natural se dice que es preternatural. A partir de esta caracterización general, conviene reparar en lo que de suyo encierran los dos sentidos más importantes de la expresión "preternatural": a saber, lo contra naturam, y lo supra naturam. Independientemente de su aplicabilidad a la definición de rapto recogida por san Alberto, lo antinatural y lo supranatural, constituyen dos expresiones que Tomás de Aquino emplea a menudo en varios de sus escritos.

El movimiento contra naturam es mejor conocido como movimiento violento, y es causa de que se imprima en el ser sobre el que actúa, un movimiento diverso al que éste desarrolla espontáneamente. Sin duda alguna, el movimiento violento genera cierta necesidad, una necesidad que, ciertamente, también posee el movimiento secundum naturam. Sin embargo, la necesidad de la violencia radica en que depende de una causa extrínseca al agente y que, como tal, permanece solo mientras permanezca la acción de la causa sobre el ser en cuestión. En cambio, la necesidad propia del movimiento secundum naturam es una necesidad intrínseca, ${ }^{6}$ que se sigue del fin propio del agente. ${ }^{7}$ Por eso afirma Tomás de Aquino que «la violencia se da cuando algo se mueve en virtud de un agente exterior, hacia algo a lo que dicho agente no tiene aptitud por su propia naturaleza». ${ }^{8}$ Para distinguir entre ambos también podría afir-

6 El movimiento secundum naturam es además un movimiento ab intrinseco, es decir, aquel por el que debido a un un principio activo propio del sujeto, éste desarrolla una operación naturalmente: v.g. el movimiento local, la sanación, etc., que se producen naturalmente, «y todas las otras operaciones del alma: vegetativas, sensitivas, intelectivas, volitivas, apetitivas, digestivas» (Tomás de Aquino, In IV Sent., dist. 22 q. 2, a. 1). Citado por Signoriello, N., Lexicon peripateticum philosophico-theologicum, Fridericus Pustet, Roma, 1931, pp. 1-2.

7 Tomás de Aquino, In Ethicorum Aristotelis expositio, lect. I, n. 387: «Violento es aquello cuyo principio es extrínseco. Pues ya hemos dicho que la violencia excluye el movimiento apetitivo. Por eso, como el apetito es un principio intrínseco, corresponde que lo violento sea por un principio extrínseco. Pero no todo aquello cuyo principio es extrínseco es violento, sino lo que es de tal manera por un principio extrínseco que no concurre el apetito interior al mismo».

8 Tomás de Aquino, In Metaphysicorum Aristotelis expositio, V, lect. VI, n. 385. 
marse que el movimiento contra naturam es un movimiento dirigido en contra del movimiento secundum naturam.

Un ejemplo de movimiento secundum naturam que Aristóteles emplea frecuentemente es el movimiento del fuego hacia arriba. Por el contrario, el movimiento del fuego hacia abajo sería ejemplo de movimiento contra naturam. Pero los calificativos natural-antinatural también pueden extenderse análogamente a los reposos. ${ }^{9}$ Así, para el fuego, permanecer abajo sería antinatural, y en cambio sería natural permanecer arriba. ${ }^{10} \mathrm{El}$ ejemplo del fuego es muy simple, porque lo natural, en este caso, puede verse en términos de cambio local. Pero como es sabido, hay otros tipos de cambio, como el aumento y la disminución de tamaño, la generación y la corrupción, o los cambios cualitativos (que son los que, probablemente, afectan al conocimiento en el rapto).

Desde esta perspectiva, un primer principio del que parte Tomás de Aquino es precisamente que el movimiento que tiene lugar en el rapto, con la elevación del alma "por fuerza de una naturaleza superior», no puede ser un movimiento violento. Pues para suscribirlo, tendría que demostrarse que la intervención elevadora de Dios, por la que el alma se despega, sustrae, aparta o aleja de la naturaleza propia, está dirigida contra el modo natural y ordinario de que dispone intrínsecamente la inteligencia humana para acceder al conocimiento de las supremas realidades inteligibles (es decir, Dios y las sustancias separadas). Y esto solo puede ser admitido por Tomás de Aquino si se comprueba que Dios puede actuar en las criaturas contra naturam.

Pero en vez de esto, Tomás de Aquino justifica en la Suma Teológica por qué Dios no actúa en las criaturas contra naturam diciendo que:

Cuando en las cosas naturales sucede algo fuera del curso ordinario de su propia naturaleza, ello puede ser de dos modos: a) uno, por la acción de algún agente que no dé a tales cosas su tendencia natural, como cuando el hombre mueve un cuerpo pesado hacia arriba, dirección hacia la que no tiende. Esto va contra la naturaleza; b) otro, por la acción de aquel agente del

9 Cf. Physica, V, 6, 230b 10-20; In Physicam Aristotelis expositio, V, cap. VI, lect. X, n. 742.

10 Cf. In Physicam Aristotelis expositio, V, cap. VI, lect. X, n. 742. 
que depende la acción natural. Esto no va contra la naturaleza. Y como el orden existente en la naturaleza depende de Dios, no va contra la naturaleza que El haga algo fuera de este orden. A este propósito dice san Agustín en XXVI Contra Faustum: Le es natural a cada ser todo lo que hiciere en él aquel de quien procede todo orden y medida en la naturaleza. ${ }^{11}$

Lo mismo que la tendencia natural del fuego es ascender, la tendencia natural del agua del mar es a descender. Y la ciencia contemporánea ha confirmado la creencia de la ciencia medieval de que el curso natural de las mareas puede ser modificado por la luna de modo que en vez de dirigirse el agua hacia abajo, presente movimientos de flujo y reflujo por los que el agua sube unas veces y baja en otras. Pero este movimiento, por el que la luna causa las mareas, no es - siguiendo la posición de Tomás de Aquino- contra la naturaleza del agua, por la razón de que es precisamente de la luna misma de quien depende también la tendencia natural de los cuerpos en la tierra, incluida el agua (al menos eso es lo que se creía en la Edad Media). Hoy se sabe que la tendencia natural del agua hacia abajo se debe a la gravedad, y no tanto a la luna misma. Pero inmersos en el esquema mental del hombre de ciencia medieval, que Tomás de Aquino tuvo que recoger y que no tenía razón para rechazar (similar a la relación que hoy en día el hombre tiene con la ciencia moderna: generalmente no se le ocurre desacreditar sus conclusiones), la luna era la que motivaba la tendencia natural del agua hacia abajo. Y así, si de la luna dependía el movimiento natural del agua de mar, el que la luna misma fuese la causa de que dicho orden natural se modificase durante las mareas, no tenía por qué tener nada de antinatural.

Algo parecido sucede en el caso del rapto. En el hombre, la acción natural de su inteligencia consiste en que ésta se dirija al conocimiento de los inteligibles por medio de la abstracción que de sus especies realiza desde las imágenes sensibles. Esto es lo natural. Por tal motivo, si el hombre llegara a conocer con su inteligencia por cualquier otro modo diferente, dicho conocimiento no tendría por qué ser antinatural -contrario a la naturaleza de su inteligencia- siempre y cuando dicho

11 Summa Theologiae, I, q. 105, a. 6, ad 1m. 
conocimiento fuese motivado o movido por el mismo agente del que depende la acción natural. Ciertamente, en el caso de las realidades sensibles, el conocimiento de ellas por parte de la inteligencia humana no depende de Dios, sino del alma misma. De esto no hay duda. Pero el asunto es más complejo. No hay que olvidar que para Tomás de Aquino la acción natural de la inteligencia humana depende (no en un sentido ontológico, pero sí en cierto modo) de Dios, ya que todo orden natural depende de Dios, incluyendo por supuesto el orden natural de la inteligencia. ${ }^{12} \mathrm{Y}$ por eso, desde este ángulo, el que Dios eleve la inteligencia humana por encima del modo ordinario con que ella conoce no sería contra naturam, tratándose de las realidades sensibles.

Pero como lo conocido en el rapto es la esencia de Dios, lo importante es ver qué sucede tratándose de Él, es decir, de una realidad de la que no es posible tener imágenes sensibles para poder conocerla. Y la conclusión de Tomás es que el alma no puede conocer la esencia de Dios solamente por su fuerza racional y en esta vida, sino que hace falta que Dios mismo actúe para lograrlo, que se una al intelecto humano como forma inteligible, de modo que Él sea, no ya solo como el objeto (quod videtur) de conocimiento, sino además el principio (quo videtur) que lo hace posible. ${ }^{13}$ De ser así, la acción de Dios, al elevar la inteligencia de alguien por encima del orden natural que le corresponde, tampoco sería contra naturam.

Así pues, determinar si el rapto es contra naturam, depende de lo que se entienda por ésta última expresión, es decir, por movimiento violento. Una definición de movimiento violento más completa (siguiendo de

12 Recuérdese la doctrina medieval de la praestitutio divina, según la cual «toda obra de la naturaleza se considera obra de una inteligencia» (De veritate, q. III, a. 1, c.). Además, así como la operación propia del hombre consiste en entender mediante la imaginación y los sentidos, la operación por la que conoce sólo lo intelectual, dejando a un lado el conocimiento de lo sensible, no es propia del mismo en cuanto hombre, sino en cuanto existe en él algo de divino. Así lo admite Aristóteles en Ethica Nicomachea, X, 11 (1177b 27), en donde considera que la felicidad en cierto sentido está por encima de la condición humana: porque el hombre en cuanto hombre sólo puede ser feliz en cuanto que hay en él algo divino, y la inteligencia humana es precisamente algo divino.

13 «Para que a Dios se le vea por esencia, es necesario que la esencia divina se una de algún modo al intelecto como forma inteligible» (De veritate, q. VIII, a. 3, c., et ad $14 \mathrm{~m}$ ), «de modo que en tal visión, la esencia divina es tanto lo visto como aquello por lo que es vista dicha esencia» (Summa contra gentes, III, 51). 
cerca lo afirmado arriba en la Suma Teológica), que no solo contemple al hecho de que la acción de un agente $(\mathbf{X})$ no esté de acuerdo con la tendencia natural de otro $(\mathbf{Y})$, sería la siguiente:

Cuando $\mathbf{X}$ no respeta la tendencia natural de $\mathbf{Y}$, obra violentamente si y solo si de $\mathbf{X}$ no depende la tendencia natural misma de $\mathbf{Y}$

En suma, en caso de darse el consecuente en esta definición bicondicional, no habrá violencia alguna. Cuando el hombre levanta una roca del suelo, obra violentamente porque da a ella una dirección distinta de aquélla hacia la que tiende naturalmente, que es abajo. Pero, además, porque el movimiento natural de la roca no depende del hombre, sino de la gravedad. De igual modo, cuando Dios eleva la inteligencia humana por encima del orden natural, no obra con violencia porque de Dios mismo dependía en cierto modo, el conocer tanto lo sensible como a Dios mismo.

\section{«Por fuerza de una naturaleza superior»}

Si el rapto no entraña de suyo un movimiento contra naturam de la inteligencia, queda por preguntarse ¿qué clase de elevación praeter naturam es la que tiene lugar en él? Es decir, ¿hay algún otro modo por el que la inteligencia pueda ser elevada desde lo natural sin que sea contrario a su naturaleza? La respuesta conduce necesariamente a un segundo tipo de movimiento praeter naturam: el movimiento supra naturam se asemeja al movimiento violento en que es efecto de una causa más alta que la propia naturaleza del agente. Éste se distingue del movimiento violento en cuanto que la causa superior no va contra la causalidad propia del agente sino, por el contrario, la asume y la eleva en la línea de su perfección en el contexto del universo. Esto ocurre de una manera extraordinaria, es decir, fuera del curso normal del ser natural en cuestión: extra naturam. ${ }^{14}$

Es importante señalar que el movimiento supra naturam no es privativo del orden teológico. Es verdad que Tomás de Aquino se refiere a cuestiones relativas al movimiento supra naturam para explicar fenómenos como los milagros. Y lo hace por medio de dos razones. En primer lugar, debido al carácter instrumental que la filo- 
sofía tenía en la Edad Media con respecto a la teología, por el que muchas cuestiones teológicas tenían que apelar a conceptos filosóficos con el fin de alcanzar una solución coherente y consistente. Y segundo, porque en el caso de los milagros, Dios opera también aquí fuera del curso normal de la naturaleza.

Pero en realidad el movimiento supra naturam nace de una consideración estrictamente filosófica, prevista en Acerca del cielo como parte de una teoría física. En esta obra, Aristóteles ha afirmado que aunque la tendencia natural del fuego es a moverse hacia arriba, y aunque la tendencia natural del aire es a moverse en sentido horizontal, en ocasiones puede suceder que el fuego y el aire se muevan circularmente, desatendiéndose con ello al orden natural de sus respectivos movimientos. Pero, además, puede ocurrir que la causa en virtud de la cual se produce ello no sea otra que la influencia de ciertos cuerpos superiores al fuego y al aire, como por ejemplo los cuerpos celestes, es decir, las estrellas. Y como el fuego y el aire, a diferencia del agua o de la tierra, son los cuerpos más cercanos al cielo, no debe extrañar que el fuego y el aire lleguen a describir en ocasiones movimientos completamente circulares como el hecho por los cometas.

Pero lo importante viene a continuación. Y es que según Tomás de Aquino, tanto el movimiento circular del fuego, lo mismo que el del aire (que ocurre merced al influjo de los cuerpos celestes), ciertamente no es natural en la línea de la perfección particular del fuego o el aire (por la que atendiendo a su naturaleza particular, no se mueven en dirección del sentido que naturalmente les compete), pero tampoco es contra naturam (porque a fin de cuentas les añade una perfección adicional que por sí mismos no tenían el fuego y el aire), sino sobre todo supra naturam, es decir, superior a su naturaleza. Forma parte del orden general del universo que unos seres se ordenen a otros, y esta ordenación producida en la línea de la perfección universal de la naturaleza es completamente natural. Por un lado, el movimiento circular no es natural al fuego o al aire. De este modo, cualquier movimiento circular presente en el fuego es un movimiento innatural. Pero el movimiento circular del fuego o del aire, producido en virtud de la influencia de un cuerpo superior, es por otro lado, natural a ellos, puesto que poseen en sí mismos la aptitud para 
ser movidos naturalmente, no por cualquier otro cuerpo, pero sí por un cuerpo superior, es decir, un cuerpo cuya naturaleza está por encima de la propia naturaleza.

Este movimiento praeter naturam que es supra naturam es precisamente el tipo de movimiento que según Tomás de Aquino se produce en el rapto. ${ }^{15} \mathrm{Y}$ lo que aquí hemos dicho acerca de los cuerpos para explicar el modo en que pueden modificar super naturam el movimiento natural de otros cuerpos, es aplicable — según Tomás de Aquino- a la modificación que pueden sufrir las almas por obra del poder divino en cuanto al modo natural que tienen para conocer lo inteligible.

En efecto, primero, nos encontramos con que en el hombre existe una operación natural, propia, en virtud de la cual es lo que es. Es sabido que la operación propia del hombre consiste en entender mediante la imaginación y los sentidos. Pero esta operación puede ser modificada cuando, sustraído de lo que sus sentidos le proporcionan, atiende a lo que va más allá de ellos. En el propio hombre es posible encontrar cierta aptitud para lograrlo, o para decirlo en términos ontológicos, cierta potencia pasiva para lograrlo, pues el alma no solo es un alma unida a un cuerpo (y conforme a lo cual precisamente se le considera alma), sino que con plena anterioridad ontológica, ${ }^{16}$ es un alma que existe de suyo (recuérdese que anima est in se), ${ }^{17}$ por esto posee una dimensión inorgánica y metacorporal, y conforme a ella se dice que tal alma es espíritu, y el espíritu tiene por objeto llegar a conocer a Dios y a otras sustancias separadas.

15 «El que la mente sea elevada por Dios mediante el rapto no es antinatural, sino superior a la facultad natural»: Summa Theologiae, II-II, q. 175, a. 1, ad 2m.

16 «El alma a la que se considera espíritu existe de suyo antes que estando unida a un cuerpo, conforme a lo cual se le considera alma»: De veritate, q. XIII, a. 1, arg. 10.

17 Quaestio disputata de anima, art. 1, c.: «Además, en el caso del alma racional debe considerarse otra cosa: de hecho, no solamente recibe las especies inteligibles sin la materia y sin sus condiciones, sino que ya no hay posibilidad de que en su operación propia tenga comunicación con ningún órgano corporal de suerte que una cosa corporal sea órgano de la intelección, como el ojo lo es de la visión. Así, por el hecho de que tiene una operación propia sin comunicación con el cuerpo, es necesario que el alma intelectiva obre por sí. Y como cada cosa obra según esté en acto, es necesario igualmente que esta alma intelectiva tenga el ser absolutamente por sí, independientemente del cuerpo». 
Claro está que la condición espiritual del hombre no basta para raptarse a sí mismo, pues sustraerse de la realidad sensible se explica en razón de un poder superior: el poder divino, que es causa eficiente del rapto humano.

El movimiento circular del fuego que es causado por los astros, y ciertamente es innatural en la línea de la perfección particular del fuego pero no lo es en la línea de la perfección universal de la naturaleza (ya que de acuerdo con ésta es completamente natural que se mueva circularmente en vez de hacerlo horizontalmente). Igualmente sucede con el rapto, en que el modo natural de la inteligencia (conocer desde lo sensible) es alterado por Dios para que Dios mismo sea conocido: es innatural en la línea de la perfección particular de la inteligencia (tomando en cuenta la naturaleza particular de ella) pero no lo es para la perfección universal de la naturaleza. El rapto forma parte del orden general del universo en que unos seres - los menos perfectos- se ordenan a otros superiores, $y$ esta ordenación producida es perfectamente natural.

La distinción entre natura particularis y natura universalis hecha aquí es muy importante porque permite resolver una posible dificultad derivada de un texto del De veritate. En este, Tomás de Aquino afirma -admitiendo como correcta la definición propuesta por Alberto según la cual la elevación del rapto «es en cierto modo antinatural»- que: «si de determinar a qué clase de movimiento pertenece el rapto llegamos a que su género consiste en una elevación, su causa eficiente es la fuerza de una naturaleza superior, el término a quo de dicho movimiento es desde lo natural, y su término in quem es ser contrario a la naturaleza». ${ }^{18}$

Aunque Tomás de Aquino ha demostrado en la Suma Teológica que Dios no obra contra la naturaleza de las criaturas. Y con la introducción de esta nueva distinción presente en varios lugares ${ }^{19}$ del corpus thomisticum nos viene a aclarar que efectivamente no hay un absoluto contra naturam, si se tiene en cuenta la naturaleza universal: todo lo que sucede en el cosmos, tiene en ella su principio.

18 De veritate, q. XIII, a. 1, c.

19 In De Caelo Aristotelis expositio, I, cap. II, lect. 4, n. 39; De veritate, q. XIII, a. 1, ad 2m; In Phyicam Aristotelis expositio, V, cap. VI, lect. X, n. 739; In De Caelo Aristotelis expositio, II, lect. IX, n. 375. 
Pero, puede ocurrir un movimiento que sea contra naturam en la línea de la naturaleza particular. Este segundo sentido es al que se está refiriendo Alberto al sostener que el rapto es «en cierto modo antinatural», y también Tomás de Aquino, al sostener que «el término in quem es ser contra la naturaleza». El rapto no es contra naturam si se tiene en cuenta la naturaleza universal, es decir, si se toma en cuenta que por rapto el hombre se une a Dios, por éste alcanza a Dios como su fin, y ello es perfectamente natural. Según la naturaleza universal, el rapto es un movimiento secundum naturam.

Y lo mismo pasa en el orden moral. Según la naturaleza universal, al ordenar a Abraham dar muerte a su hijo Isaac, Dios no le ordena algo que contradiga el fin particular de Abraham; dicha orden representaría ello solo en apariencia, una violación de la ley; pero en realidad no representa tal violación, porque la misma ley ha sido dada por Dios con un fin, a saber: unir al hombre con Él. En este caso, al igual que en el rapto, Dios no ha hecho otra cosa que abrir vías alternativas para cumplir ese fin, un fin universal y superior al fin propio que tiene el hombre particular, y por tanto, no hay que creer que existe contradicción alguna en ello.

Tomás de Aquino no puede ser más claro en este punto que en De veritate. Allí, tras definir la naturaleza particular como «la que es propia de cada cosa», y la universal, como «aquella que abarca el orden de todas las causas naturales», ${ }^{20}$ añade que algo puede ser natural o contra naturaleza según la naturaleza particular, y según la naturaleza universal: por ejemplo, la degeneración y acabamiento que sufren los ancianos, es contra su naturaleza particular, pero es natural a ellos según su naturaleza universal, en virtud de la cual todo lo compuesto por contrarios es sujeto de corrupción. Y concluye que debido a que el orden universal de las causas es tal que las inferiores son movidas por las superiores,

todo movimiento de una naturaleza inferior producido por la impresión de una naturaleza superior, bien sea en lo corporal -como en el caso del movimiento circular del fuego-o en lo espiritual

De veritate, q. XIII, a. 1, ad 2m. 
- como en el caso del rapto- es natural según su naturaleza universal, mas no siempre según su naturaleza particular, sino solo cuando la impresión misma de la naturaleza superior sobre la naturaleza inferior es conforme a la naturaleza de ésta última. ${ }^{21}$

El mejor ejemplo de algo en el rapto que se opone a la naturaleza particular del intelecto $-\mathrm{y}$ curiosamente el único en que Tomás de Aquino afirma taxativamente que el rapto es contra naturam - aparece en De veritate. Tomás de Aquino está consciente (de acuerdo a lo que afirma san Agustín) de que «la inteligencia humana conoce a Dios naturalmente». ${ }^{22}$ Esto es incuestionable. Sin embargo, advierte que dicho sentido natural se aplica por san Agustín cuando se trata de conocer a Dios a través de las cosas sensibles, principalmente porque nos son inteligibles los efectos de Dios.

Nuevamente se impone la opinión seguida por Tomás de Aquino en otros lugares, ${ }^{23}$ de que a partir de la observación de la naturaleza y de los efectos admirables, llegamos a la existencia de Dios. Esto quiere decir solo una cosa: que lo afirmado por san Agustín se aplica al acceso de Dios en cuanto a su existencia se refiere. Pero si de llegar a conocer a Dios en su esencia misma se trata, Tomás de Aquino solo tiene una respuesta en $D e$ veritate: ello es definitivamente imposible en esta vida para el intelecto humano. ${ }^{24}$ Tan imposible, como lo sería el que un niño naciera con la

21 De veritate, q. XIII, a. 1, ad 2m. Impresión que no sucede en el rapto, pues Dios no hace que el hombre vea a Dios en su esencia a través de los sentidos, sino justamente sustrayéndose de ellos, según se dice en De veritate, q. XIII, a. 3, c. Como ya ha dicho san Agustín, en el rapto se es raptado de los sentidos corporales "para ser transportado como a la región de las cosas inteligibles o intelectuales, donde se contempla sin ninguna imagen corporal la verdad patente»: Super Genesim ad litteram, IX, cap. 19.

22 De veritate, q. XIII, a. 1, arg. 1.

23 El más famoso de todos ellos es Summa Theologiae, I, q. 2, a. 1, arg. 2-3.

24 «Tratándose de la inteligencia humana debe decirse que en cualquier estado en que se encuentre le es natural conocer a Dios: pero en el estado presente de vida, es decir, mientras aún se encamina hacia Él, lo natural es que lo conozca a través de las creaturas sensibles; en cambio es natural que alcance el conocimiento de Dios por sí misma al concluir su actual peregrinar, es decir, en el estado de bienaventuranza. Y por ello, si en el estado presente de vida se elevara al conocimiento de Dios según el estado de bienaventuranza, ello sería contra naturaleza, así como sería contra naturaleza que un niño recién nacido tuviera barba»: 
cantidad de masa corporal que le corresponde a un adulto; tan imposible, como el que un recién nacido naciese, por ejemplo, con barba, por citar el ejemplo que Tomás de Aquino toma de Maimónides. ${ }^{25}$

Y la razón es muy simple. Una actividad (como conocer a Dios) llevada a cabo por una facultad (la inteligencia humana) puede ser natural si se está llevando a cabo en el momento adecuado de su desarrollo; es decir, es natural que la inteligencia realice cierta actividad una vez está en perfectas condiciones naturales para ello, dado que su mismo ser así se lo permite. Pero será contra su naturaleza, si resulta que pudiera llevarla a cabo - ciertamente con gran admiración de los otros- mientras aún no ha llegado dicho momento, mientras está aún por alcanzar el desarrollo perfecto que requiere para ello.

Esto es precisamente lo que ocurre en el rapto: la naturaleza particular de la inteligencia es anticipada por un poder divino con el propósito que de dicha naturaleza cuente con la aptitud de conocer a Dios en su esencia desde este momento, en esta vida, sin esperarse a llegar a la otra para conocerlo por sí misma (con las debidas reservas que esta última expresión encierra). Lo natural a la inteligencia, pues, sería que alcanzara dicho conocimiento como lo alcanza la mayoría de las almas, es decir, que no lo alcanzara sino hasta llegar al estado de bienaventuranza. Y si lo alcanza desde ahora, dice Tomás de Aquino, «ello será contra naturaleza». ${ }^{26}$

De veritate, q. XIII, a. 1, arg. 1.

25 Dux neutrorum, II, c. 18.

26 De veritate, q. XIII, a. 1, ad 1m: «Y si en el estado presente de vida se elevara al conocimiento de Dios según el estado de bienaventuranza, ello será contra naturaleza».

En ciertas obras teológicas, es posible encontrar que Tomás de Aquino no rechaza la violencia para poder adquirir la fe: «Mucho mejor es enseñar a los hombres a adorar a Dios, que obligarlos con la pena; y a muchos aprovechó (lo que probamos por la experiencia) ser obligados primero por el dolor o el temor para que, después, pudiesen ser enseñados o para que después pusiesen en práctica lo que ya habían aprendido por las palabras. Así como son mejores aquéllos a quienes dirige el amor, así hay muchos a quienes corrige el temor. Aprendan del apóstol san Pablo que Jesucristo primero obligó y después enseñó» (Tomás de Aquino, Catena aurea Super Matthaeum, cap. V, vv. 38-42). Así, si no se descarta un movimiento contra naturam por lo que toca a la adquisición de la fe, con mayor razón, tampoco se descarta la violencia en el caso del rapto. 
Así, pues, atendiendo a que el rapto es exclusivamente contra naturaleza en cuanto se opone a la naturaleza particular de la inteligencia, se tiene que no puede ser contra naturaleza absolutamente. Y por ello no ha tenido que decir el rapto sí es contra naturam, como si fuese una respuesta a todas las observaciones (hechas por ciertos académicos contra su maestro, san Alberto) orientadas a demostrar que el rapto es algo natural.

Más aún, el tono adoptado por Tomás de Aquino sigue siendo el mismo que ha mantenido hasta aquí: el rapto se produce cuando Dios da más de lo que le corresponde a la naturaleza humana. Con ello no se atenta en absoluto contra la justicia divina ni se actúa contra la naturaleza humana, sino simplemente se premia a ésta con un acto de generosidad divina. Aquéllos pensaban que era inadmisible que Dios actuara injustamente, ya que «la justicia divina consiste en dar a cada cosa según la medida y dignidad que les corresponde», y Dios no podía hacer nada contra su justicia. Esto es verdad: Dios nunca hace nada contra su justicia. Pero sí puede ir más allá de ella. Ir contra la justicia sería sustraerle a alguno lo que le pertenece, es decir, robarle lo que se le debe, como ocurre frecuentemente entre los hombres. Pero si alguien entre los hombres nos da lo que no se nos debe, ello no es contrario a la justicia, sino que es no contentarse con darnos lo que nos toca: esto es ir más allá de la justicia. Esto es lo que Dios hace en el rapto cuando eleva la inteligencia humana en vida por sobre aquello a lo que ésta realiza por su propia naturaleza.

La razón anterior explica por qué tampoco es contra naturaleza que el alma reciba un bien (e.g. dicha elevación) aunque éste no haya sido obtenido por los méritos hechos por el alma misma. Por ejemplo, méritos tras haber obrado voluntariamente y conforme a la propia razón, lo cual es una de las mayores bondades que suelen caracterizar a los actos humanos. Existen ciertas operaciones que, a pesar de ser obras de la inteligencia divina, la naturaleza ha prescrito que alcancen su fin propio naturalmente, es decir, por un movimiento que procede de ellas mismas y no por fuerza de una naturaleza superior. Es posible que los árboles que crecen naturalmente, o los pájaros que se nutren espontáneamente, realicen tales operaciones debido a que los principios de esas operaciones están instanciados en los seres que las ejecutan de una manera tal que con toda propiedad se dice que son parte de la naturaleza de ellas. 
Mas esto no tiene por qué ser así tratándose de la mente humana que conoce a Dios en su esencia por medio del rapto. El rapto procede exclusivamente del poder de Dios, y por eso ha afirmado del rapto que «su causa eficiente es la fuerza de una naturaleza superior ${ }^{27}$ y no solo la causa final, que es lo que en efecto constituye Dios respecto de las demás operaciones presentes en la naturaleza.

Para las otras operaciones naturales, el principio de ellas está en ellas mismas, y el fin al que tienden es Dios. Para el rapto de la inteligencia, Dios es, además de su fin, su principio. Y hablando del principio y fin, solo llegar al fin de dicho movimiento natural es natural, no así el principio de dicho movimiento ordenado a Él. ${ }^{28}$ No es éste el lugar de tratar acerca de las cualidades que tendría o no que haber en los hombres para que fuesen sujetos de rapto. Lo importante es destacar que Dios lo concede independientemente de la voluntad humana, no que ello contradice la voluntad humana.

¿Cómo va a ser contra naturaleza la presencia de Dios al intelecto humano - no obstante ser Dios un inteligible demasiado intenso- si en vez de destruirse - como correspondería al sentido, que ante un sensible demasiado intenso llega a destruirse al punto de no poder conocer después otros sensibles menos intensos- el intelecto logra en cambio confortarse plenamente a su objeto, ${ }^{29}$ de tal modo que después puede conocer otros inteligibles menos intensos?

27 De veritate, q. XIII, a. 1, c.: «Así, pues, al describir el rapto como cierto movimiento, llegamos al fin a que su género consiste en una elevación, y a que su causa eficiente es la fuerza de una naturaleza superior».

28 De lo anterior se desprende una conclusión. El alma no puede adquirir el hábito del rapto, porque el hábito otorga a quien lo tiene la capacidad de producir los actos de los que depende el hábito, cuando uno lo quiere y tantas veces se quiere (idea perteneciente originariamente a Averroes, pero usada también por Tomás de Aquino en De malo, q. I, a. 5, c.: «no por esto mismo que alguno tiene el hábito de la gramática, habla bien: pues el que tiene el hábito puede no usar de él, o actuar contra él; como cuando el gramático conscientemente comete un solecismo; y entonces hace uso correcto de su arte, cuando él quiere») cuando la verdad es que el rapto se produce por voluntad divina y no a instancias del hombre que lo quiere. Más aún, para que haya hábito se requiere normalmente la repetición sucesiva de diversos actos en un mismo sentido, hecho que difícilmente se obtiene con el rapto dado su carácter más bien esporádico y extra ordinem.

29 De veritate, q. XIII, a. 1, ad 6m: «cuando el intelecto percibe algún inteligible demasiado intenso queda confortado de modo tal que después puede conocer mejor los inteligibles menos intensos». 


\section{Conclusión}

Aunque en la Suma Teológica Tomás de Aquino haya afirmado primeramente que Dios no obra contra la naturaleza de las criaturas, al introducir la distinción mencionada en De veritate (entre naturaleza particular y naturaleza universal), puede decir de qué modo aquello que Dios causa sobre las criaturas puede ir en contra la naturaleza de éstas. El rapto solo puede ser contra naturaleza de la inteligencia en la línea de su naturaleza particular. Ello quiere decir que todo lo que corresponda al rapto que se oponga a la naturaleza particular de la inteligencia, es decir, al modo natural en el que ella conoce, será sin duda contra naturam.

Se desprende del análisis general de las respuestas dadas por Tomás de Aquino a las objeciones presentadas (por quienes aseguran que es natural que la inteligencia conozca a Dios en su esencia) que el rapto no es natural porque lo que está por encima de la naturaleza humana, y de su particular modo de conocimiento, es completamente producido desde fuera en la línea de la perfección universal de la naturaleza. Esto añade una perfección a la naturaleza particular de la inteligencia, y por tanto, no es contra naturam, sino más bien supra naturam.

Basta con que sea supra naturam para que, según Tomás de Aquino, no sea secundum naturam. Y por ello, en vez de considerar como su última palabra (la opinión expuesta en De veritate) que en el rapto su término in quem es ser contra naturam, hay que creer que en Tomás de Aquino prevaleció finalmente (como, de hecho, prevalecieron cronológicamente las opiniones de madurez presentadas en la Suma Teológica - en la que corona lo que ha dicho en De veritate-) la opinión de que el rapto no es natural, sino más bien algo preternatural, es decir, algo superior a la naturaleza humana.

\section{Bibliografía}

\section{Bibliografía principal}

Sancti Thomae Aquinatis. Quaestiones disputatae de veritate. Opera Omnia Iussu Leonis XIII P.M. edita Tomus XXII, vol. 1. Roma: Editori di san Tommaso, 1975-1976. 
Tomás de Aquino. De veritate, cuestión 8, El conocimiento de los ángeles. Pamplona: Cuadernos de Anuario Filosófico, 2003.

Tomás de Aquino. De veritate, cuestión 13, Tratado sobre el arrebato místico. Pamplona, Cuadernos de Anuario Filosófico, 1999.

Tomás de Aquino. Comentario de la Ética a Nicómaco. Buenos Aires, CIAFIC ediciones, 1983.

Tomás de Aquino. Comentario a la Física de Aristóteles. Pamplona, Eunsa, 2011.

Tomás de Aquino. Suma de Teología, vol. 1: Parte I. Madrid: B.A.C., 2001.

Tomás de Aquino. Suma de Teología, vol. 3: Parte II-II (a). Madrid: B.A.C., 1995.

Tomás de Aquino. Suma de Teología, vol. 4: Parte II-II (b). Madrid: B.A.C., 1994.

Tomás de Aquino. Suma contra los gentiles, vol. 2, libros 3-4. Madrid: B.A.C., 2007.

Tomás de Aquino. Cuestiones disputadas sobre el alma. Pamplona: Eunsa, 1999.

Tomás de Aquino. Comentario al libro de Aristóteles sobre el cielo y el mundo. Pamplona: Eunsa, 2002.

Tomás de Aquino. Catena aurea a Mateo, vol. I, primera parte. Buenos Aires: Cursos de Cultura Católica, 1948.

Tomás de Aquino. Cuestiones disputadas sobre el mal. Pamplona: Eunsa, 2015.

Bibliografía secundaria

Agustín de Hipona. Interpretación literal del Génesis. Pamplona: Eunsa, 2006.

Aristóteles. Física. Madrid: Gredos, 2007.

Aristóteles. Etica Nicomáquea. Madrid: Gredos, 2000.

Maimónides. Guía de Perplejos. México: Conaculta, 2001.

Nuntio Signoriello. Lexicon peripateticum philosophico-theologicum. Roma: Fridericus Pustet, 1931.

Pseudo Dionisio Areopagita. Obras completas. Madrid: B.A.C., 1995. 